\title{
Cannabinoid type-1 receptor gene polymorphisms are associated with central obesity in a Southern Brazilian population
}

\author{
Janaína P. Jaeger ${ }^{\mathrm{a}}$, Vanessa S. Mattevi ${ }^{\mathrm{b}}$, Sidia M. Callegari-Jacques ${ }^{\mathrm{a}, \mathrm{c}}$ and Mara H. Hutz ${ }^{\mathrm{a}, *}$ \\ ${ }^{a}$ Departamento de Genética, Instituto de Biociências, Universidade Federal do Rio Grande do Sul, Caixa Postal \\ 15053, 91501-970 Porto Alegre, RS, Brazil \\ ${ }^{\mathrm{b}}$ Departamento de Ciências Fisiológicas, Fundação Faculdade Federal de Ciências Médicas de Porto Alegre, \\ 90050-170 Porto Alegre, RS, Brazil \\ ${ }^{\mathrm{c}}$ Departamento de Estatística, Instituto de Matemática, Universidade Federal do Rio Grande do Sul, Av. Bento \\ Gonçalves, 9500, 91509-900 Porto Alegre, RS, Brazil
}

\begin{abstract}
The CB1 cannabinoid receptor and its endogenous ligands, the endocannabinoids, are involved in energy balance control, stimulating appetite and increasing body weight in wasting syndromes. Different studies have investigated the relationship between polymorphisms of the cannabinoid receptor 1 ( CNR1) gene and obesity with conflicting results. In the present study, we investigated the 1359G/A (rs1049353), 3813A/G (rs12720071) and 4895A/G (rs806368) polymorphisms in the CNR1 gene in a Brazilian population of European descent. To verify the association between these variants and obesity-related traits in this population, 756 individuals were genotyped by PCR-RFLP methods. The $4895 \mathrm{G}$ allele was associated with waist to hip ratio (WHR) $(P=0.014 ; P=0.042$ after Bonferroni correction). An additive effect with the GAA haplotype was associated with WHR $(P=0.028)$, although this statistical significance disappeared after Bonferroni correction $(P=0.084)$. No significant association was observed between the genotypes of the $1359 \mathrm{G} / \mathrm{A}$ and $3813 \mathrm{~A} / \mathrm{G}$ polymorphisms and any of the quantitative variables investigated. Our findings suggest that $C N R 1$ gene polymorphism is associated with central obesity in this Brazilian population of European ancestry.
\end{abstract}

Keywords: Obesity, CNR1, polymorphisms, WHR, BMI

\section{Introduction}

The endocannabinoid (EC) system is an endogenous and physiological system that plays a key role in the regulation of food intake and fat accumulation. It can also modulate glucose and lipid metabolism through its effects on peripheral tissues. At least two 6-proteincoupled cannabinoid receptors have been identified [7, 26]. The first cannabinoid receptor, which is the most

*Corresponding author: Prof. Mara H. Hutz, Departamento de Genética, Instituto de Biociências, UFRGS, Caixa Postal 15053, 91501-970 Porto Alegre, RS, Brazil. Tel.: +55 513308 6720; Fax: +55 513343 5850; E-mail: mara.hutz@ufrgs.br. abundant in the brain, was named CB1 after the cloning of the second cannabinoid receptor subtype CB2, mostly present in immune cells [15]. CB1 is expressed abundantly in several areas of the central nervous system. These areas include the hippocampus, ganglia, cerebral cortex, cerebellum, limbic system and hypothalamus [16]. Early studies showed a scattered presence of CB1 receptors in peripheral organs, such as the adipose tissue and gastrointestinal system, which are key organs involved in the regulation of food intake $[3,25]$. On the other hand, CB2 does not play a part in this regulation system.

Obesity is a major predisposing factor for several chronic diseases including coronary artery disease and diabetes. It arises from complex interactions between 
genetics and environment that alter the delicate mechanism regulating energy expenditure and food intake. Feeding control determines the sensation of satiety and hunger through an interplay mechanism between internal signals (i.e. leptin) and environmental factors. The endocannabinoid system may influence food intake by regulating the expression and/or action of several hypothalamic anoretic and orexigenic mediators $[6,14]$. Signals of peripheral origins modulate the neurochemical activation of hypothalamic neurons. CB1 and endocannabinoids are able to cross-talk to those signals, such as leptin and adiponectin, secreted by adipocytes. In the central nervous system (CNS), endocannabinoids can act as neurotransmitters, representing an important modulatory mechanism of neuronal transmission. In the hypothalamus, the changes in endocannabinoid levels seem to be inversely correlated with some changes that are known to occur in leptin blood levels [21]. Indeed, leptin decreases endocannabinoid levels in the hypothalamus, as much as it does for other orexigenic mediators. On the other hand, animal models of obesity (ob/ob; $d b / d b$ mice or $f a / f a$ Zucker rats) have increased endocannabinoid levels [8]. Moreover, ventromedial hypothalamic administration of anadamide (one CB1 endogenous ligand) in pre-satiated rats resulted in CB1 dependent hyperphagia [17]. These findings are in agreement with the devastating impact that the disruption of CB1 signaling has on feeding and growth in young mice [9]. Recently, it has been demonstrated that CB1 mRNA co-expresses with corticotrophin releasing hormone $(\mathrm{CRH})$, cocaine-amphetamine related transcript (CART), melanin concentrating hormone $(\mathrm{MCH})$ and prepro-orexin in hypothalamic neurons [6].

All these data taken together highlight the role of the endocannabinoid system in feeding and energy balance regulation. Indeed, it was reasonable to hypothesize that from a pharmacological point of view, inhibition of the endocannabinoid system through antagonism of the cannabinoid CB1 receptor may be an effective therapeutic approach to treat human obesity.

The cannabinoid receptor $1(C N R 1)$ gene was mapped to chromosome 6q14-15 [13]. Several human CNRI gene polymorphisms have been reported. Among them a silent mutation resulting in the substitution from $\mathrm{G}$ to A nucleotide position 1359 (rs1049353) in codon 453 (Thr) [11] and two exon 4 variants in the 3'UTR region, 3813A/G (rs12720071) and 4895A/G (rs806368) [33]. Although two previous studies have shown association of the $1359 \mathrm{G} / \mathrm{A}$ variant with obesityrelated traits in European populations [12,23], two other studies failed to confirm this association $[1,22]$. The two exon 4 polymorphisms were recently associated with abnormal body mass index (BMI) and body fat distribution in Italian middle-aged man [28].

Since the importance of the aforementioned gene variants to the development of obesity in human populations is still a matter of controversies, the aim of this study was to determine whether genetic polymorphisms at the CNRI gene contribute to variation in obesityrelated phenotypes in an European-derived Southern Brazilian population, and to examine these results in the context of current findings related to the proposed functions for these endocannabinoids.

\section{Material and methods}

\subsection{Subjects}

The study was performed in 756 individuals of European descent residing in Porto Alegre, the capital of Brazil's southernmost state. This city was founded in 1752 by 60 Caucasian couples from the Azores Islands. Currently the population is still mainly of Portuguese descent, but Italians, Spaniards and Germans have also contributed to its gene pool [29]. The 447 women and 309 men most of them of low socio-economic status, were selected at random at the Clinical Analysis Laboratory of the Pharmacy School of the Federal University of Rio Grande do Sul among those who came from several city health centers for free routine blood determinations. The sample collection was performed between 2001-2002. The Ethics Committee of the Federal University of Rio Grande do Sul approved the study protocol and all individuals gave their written informed consent prior to the investigation. A questionnaire was completed, including smoking habits, alcohol consumption and regular physical activity in leisure time. Exclusion criteria were occasional smoking, secondary hyperlipidemia due to renal, liver or thyroid disease, and pregnant women. In addition, individuals with a previous history of diabetes mellitus or fasting glucose levels above $6.9 \mathrm{mmol} / \mathrm{l}$ [2] were excluded from the analyses to avoid the confounding effects of diabetes and its treatment on obesity-related traits.

\subsection{Anthropometric measurements and biochemical analysis}

The subjects attended the laboratory in the morning after a $12 \mathrm{~h}$ fast. Blood samples were collected and weight and height were measured. Height was 
Table 1

Anthropometric, biological, and lifestyle characteristics of 756 individuals investigated (quantitative data are expressed as mean \pm SD)

\begin{tabular}{|c|c|c|c|c|c|c|}
\hline & Women & Men & $\mathrm{P}$-value & Cases & Controls & $\mathrm{P}$-value \\
\hline $\mathrm{n}$ & 447 & 309 & & 322 & 434 & \\
\hline Age $(\text { years })^{\mathrm{a}}$ & $42.8 \pm 15.6$ & $46.0 \pm 14.3$ & 0.004 & $40.8 \pm 15.3$ & $46.5 \pm 14.6$ & 0.0001 \\
\hline Weight $(\mathrm{Kg})^{\mathrm{a}}$ & $65.9 \pm 13.2$ & $77.0 \pm 13.3$ & 0.0001 & $59.8 \pm 8.5$ & $78.4 \pm 12.4$ & 0.0001 \\
\hline Height $(\mathrm{cm})^{\mathrm{a}}$ & $158.4 \pm 6.9$ & $170.6 \pm 6.9$ & 0.0001 & $163.7 \pm 9.3$ & $163.1 \pm 9.0$ & 0.329 \\
\hline Body mass index $\left(\mathrm{Kg} / \mathrm{m}^{2}\right)^{\mathrm{a}}$ & $26.3 \pm 5.1$ & $26.5 \pm 4.3$ & 0.596 & $22.2 \pm 2.0$ & $29.4 \pm 3.7$ & 0.0001 \\
\hline Waist to hip ratio $(\mathrm{cm})^{\mathrm{a}}$ & $0.85 \pm 0.07$ & $0.93 \pm 0.10$ & 0.0001 & $0.85 \pm 0.08$ & $0.91 \pm 0.08$ & 0.0001 \\
\hline Waist circumference $(\mathrm{cm})^{\mathrm{a}}$ & $88.7 \pm 12.5$ & $95.4 \pm 11.1$ & 0.0001 & $82.1 \pm 8.4$ & $98.3 \pm 10.1$ & 0.0001 \\
\hline HDL-Chol $(\mathrm{mg} / \mathrm{dL})^{\mathrm{b}}$ & $46.4 \pm 11.5$ & $42.2 \pm 12.5$ & 0.0001 & $46.8 \pm 12.0$ & $43.2 \pm 11.9$ & 0.0001 \\
\hline LDL-Chol $(\mathrm{mg} / \mathrm{dL})^{\mathrm{b}}$ & $135.7 \pm 41.3$ & $131.3 \pm 41.9$ & 0.272 & $126.6 \pm 41.1$ & $139.5 \pm 41.1$ & 0.0001 \\
\hline Triglycerides $(\mathrm{mg} / \mathrm{dL})^{\mathrm{b}}$ & $127.2 \pm 82.3$ & $152.9 \pm 24.1$ & 0.0001 & $111.9 \pm 74.4$ & $156.7 \pm 114.8$ & 0.0001 \\
\hline Glycaemia $(\mathrm{mg} / \mathrm{dL})^{\mathrm{b}}$ & $88.6 \pm 11.3$ & $93.6 \pm 22.8$ & 0.0001 & $87.6 \pm 17.3$ & $92.8 \pm 16.5$ & 0.0001 \\
\hline Physically inactive $(\%)^{\mathrm{c}}$ & 66.0 & 43.4 & 0.0001 & 43.3 & 56.7 & 0.299 \\
\hline Current smokers $(\%)^{\mathrm{c}}$ & 34.5 & 40.5 & 0.107 & 63.1 & 36.9 & 0.447 \\
\hline Alcohol consumption $(\%)^{\mathrm{C}}$ & 33.1 & 58.9 & 0.0001 & 56.3 & 43.7 & 0.416 \\
\hline
\end{tabular}

Cases correspond to normal-weight $(\mathrm{BMI}<25)$ and controls to obese plus overweight $(\mathrm{BMI} \geqslant 25)$ individuals.

anpaired $t$-test.

${ }^{\mathrm{b}}$ Mann-Whitney test.

${ }^{\mathrm{c}}$ Chi-Square $\left(\chi^{2}\right)$ test.

measured to the nearest centimeter using a rigid stadiometer. Weight was measured to the nearest $0.1 \mathrm{Kg}$ using an electronic calibrated balance scale. Body mass index (BMI) was expressed as weight $(\mathrm{Kg})$ divided by the square of height $\left(\mathrm{m}^{2}\right)$. Waist circumference was measured at mid-level between the lower rib margin and the iliac crest [31], and hip circumference at the widest trochanters to the nearest $\mathrm{mm}$; all measurements were performed by the same person. Overweight was defined for a BMI over $25 \mathrm{Kg} / \mathrm{m}^{2}$ and obesity for a BMI over $30 \mathrm{Kg} / \mathrm{m}^{2}$, according to the World Health Organization criteria [32]. Total cholesterol (TC), HDL cholesterol, triglycerides (TG) and glucose were determined by conventional enzymatic methods. LDL cholesterol was calculated according Friedewald et al. [10].

\subsection{DNA analysis}

Genomic DNA was extracted from $5 \mathrm{ml}$ anticoagulated venous blood samples using a salting out method [19]. The polymorphic sites 1359G/A, $3813 \mathrm{~A} / \mathrm{G}$ and $4895 \mathrm{~A} / \mathrm{G}$ at the CNRl gene were genotyped by PCR-RFLP methods as previously described [11,28]. Oligonucleotides used to amplify these variants were: forward 5'-GAAAGCTGCATCAAGA GCCC-3' and reverse 5' -TTTTCCTGTGCTGCCAGG G-3' for the 1359G/A variant; forward 5'-GATGAAGG CTCAGGGTGCTAGAGG-3' and reverse 5'-TAGTGC TGTCAGCCCCATGTCCC-3' for the 3813A/G variant; forward 5'-GAGACCACCCATATCATGCACAC A-3' and reverse 5'-AACTCTGATCCCCAGTAGGCC
TAG-3' for the 4895A/G variant. The amplicons were digested with restriction endonucleases $\mathrm{MspI}$ (for 1359G/A), HinfI (for 3813A/G) and FokI (for $4895 \mathrm{~A} / \mathrm{G})$.

\subsection{Statistical analysis}

Allele frequencies were estimated by gene counting. The agreement of genotype frequencies to HardyWeinberg expectations was tested using the goodness of fit chi-square test. Allele and genotype frequencies between normal-weight $\left(\mathrm{BMI}<25 \mathrm{~kg} / \mathrm{m}^{2}\right)$ and overweight/obese $\left(\mathrm{BMI} \geqslant 25 \mathrm{~kg} / \mathrm{m}^{2}\right)$ groups were compared by chi-square tests.

Multiple linear regression analyses were used to model BMI and WHR on genotypes. These analyses were performed with BMI and WHR as dependent variables and age, physical activity, smoking, alcohol consumption, gender, HDL and LDL cholesterol, triglycerides and glycaemia as covariates. Age and serum lipids as well as glucose concentrations entered as continuous variables, and lifestyle factors were included as dichotomic variables. Interactions between SNPs and all covariates were tested. The statistical analysis was performed using the SPSS ${ }^{\circledR}$ 13.0.0 package.

Haplotype frequencies and linkage disequilibrium were estimated using the Multiple Locus Haplotype Analysis (version 2.0) [20]. Haplotype associations with BMI and WHR were performed by multiple linear regression analysis as described above. Two sided $\mathrm{p}$-values $<0.05$ were considered for statistical significance. Bonferroni correction for multiparametric testing was applied when appropriate. 
Table 2

Genotype and allele frequencies of CNR1 1359G/A, CNR1 3813 A/G and CNR1 4895 $\mathrm{A} / \mathrm{G}$ gene variants in normal-weight $(\mathrm{BMI}<25)$ and obese plus overweight $(\mathrm{BMI} \geqslant 25)$ individuals

\begin{tabular}{|c|c|c|c|c|c|c|c|}
\hline \multirow[b]{2}{*}{ Genotypes } & \multicolumn{2}{|c|}{$\mathrm{BMI}<25$} & \multicolumn{2}{|c|}{$\mathrm{BMI} \geqslant 25$} & \multirow[b]{2}{*}{ Alleles } & \multicolumn{2}{|c|}{ Frequencies } \\
\hline & $\mathrm{n}$ & $\mathrm{f}$ & $\mathrm{n}$ & $\mathrm{f}$ & & $\mathrm{BMI}<25$ & $\mathrm{BMI} \geqslant 25$ \\
\hline \multicolumn{8}{|c|}{ CNR1 $1359 \mathrm{G} / \mathrm{A}$} \\
\hline $\mathrm{A} / \mathrm{A}$ & 16 & 0.05 & 18 & 0.04 & A & 0.22 & 0.22 \\
\hline $\mathrm{A} / \mathrm{G}$ & 106 & 0.34 & 152 & 0.36 & $\mathrm{G}$ & 0.78 & 0.78 \\
\hline $\mathrm{G} / \mathrm{G}$ & 199 & 0.61 & 255 & 0.60 & $\mathrm{P}$-value ${ }^{\mathrm{a}}$ & \multicolumn{2}{|c|}{1.0} \\
\hline \multicolumn{8}{|c|}{ CNR1 $3813 \mathrm{~A} / \mathrm{G}$} \\
\hline $\mathrm{A} / \mathrm{A}$ & 248 & 0.79 & 335 & 0.78 & A & 0.89 & 0.89 \\
\hline $\mathrm{A} / \mathrm{G}$ & 62 & 0.20 & 92 & 0.21 & G & 0.11 & 0.11 \\
\hline $\mathrm{G} / \mathrm{G}$ & 3 & 0.01 & 2 & 0.01 & $\mathrm{P}$-value ${ }^{\mathrm{a}}$ & \multicolumn{2}{|c|}{1.0} \\
\hline \multicolumn{8}{|c|}{ CNR1 $4895 \mathrm{~A} / \mathrm{G}$} \\
\hline $\mathrm{A} / \mathrm{A}$ & 167 & 0.53 & 217 & 0.50 & A & 0.73 & 0.71 \\
\hline $\mathrm{A} / \mathrm{G}$ & 130 & 0.41 & 179 & 0.42 & G & 0.27 & 0.23 \\
\hline $\mathrm{G} / \mathrm{G}$ & 20 & 0.06 & 34 & 0.08 & $\mathrm{P}$-value ${ }^{\mathrm{a}}$ & \multicolumn{2}{|c|}{0.45} \\
\hline
\end{tabular}

$n=$ number of individuals.

$f=$ genotype frequencies.

${ }^{\mathrm{a}} \chi^{2}$ - test between allele frequencies.

\section{Results}

Anthropometric, biological and lifestyle characteristics of the investigated subjects are summarized in Table 1 . The individuals were between 15 and 85 years old $(44.1 \pm 15.1)$, being $40.9 \%$ males. Most individuals $(42.6 \%)$ had a normal weight $\left(\mathrm{BMI}<25 \mathrm{~kg} / \mathrm{m}^{2}\right)$, while $36.9 \%$ could be classified as overweight and $20.5 \%$ were obese $\left(\right.$ BMI $\left.\geqslant 30 \mathrm{~kg} / \mathrm{m}^{2}\right)$. No differences in genotype and allele frequencies, BMI and smoking were observed between male and female subjects but, as expected, a smaller waist to hip ratio (WHR) was observed in normal weight individuals $(P<0.0001)$.

No differences in genotype and/or allele frequencies were observed between normal-weight and overweight/obese groups for the three polymorphisms investigated (Table 2). The same result was obtained when comparing normal and obese individuals (BMI $\geqslant 30 \mathrm{~kg} / \mathrm{m}^{2}$; data not shown). All genotypes were in Hardy-Weinberg equilibrium.

Multiple linear regression analysis of BMI and WHR on the CNRI polymorphisms and other potential confounders are shown in Tables 3, 4 and 5 for $1359 \mathrm{G}>\mathrm{A}$, $3813 \mathrm{~A}>\mathrm{G} 4895 \mathrm{~A}>\mathrm{G}$ polymorphisms respectively. These analyses were performed with BMI and WHR as continuous traits using the whole sample. Since the less frequent alleles for the three $C N R 1$ polymorphisms were present only in few individuals, the analyses were performed according to a dominant model pooling heterozygous and less frequent allele homozygous individuals. When controlled by confounders, the 4895G allele was associated with WHR $(P=0.014$; $P=0.042$ after Bonferroni correction; statistical pow- er $=0.71)$, but not with BMI $(P=0.958)$ (Table 5). The multiple $\mathrm{R}^{2}$ of the regression model with the CNRI 4895 polymorphism and covariates was 0.368 ; the partial $\mathrm{R}^{2}$ for CNR1 4895 was 0.008 . The effect of the gene can also be evaluated through the difference between the adjusted means of the genotypes. The WHR mean \pm SE were: $0.877 \pm 0.003$ for homozygous AA individuals, and $0.889 \pm 0.003$ for $\mathrm{AG}+\mathrm{GG}$ individuals. The difference between means was 0.012 (CI 95\%: 0.0024-0.0211). No significant association was observed between the genotypes of the 1359G/A and $3813 \mathrm{~A} / \mathrm{G}$ polymorphisms and any of the quantitative variables investigated (Tables 3 and 4). No second order interactions were observed between each SNP and covariates (data not shown).

The examination of pair-wise linkage disequilibrium (LD) indicated that the three polymorphisms were in strong LD $\left(1359 \mathrm{G} / \mathrm{A}\right.$ and $3813 \mathrm{~A} / \mathrm{G}-\mathrm{D}^{\prime}=0.87$ and $P<0.0001 ; 1359 \mathrm{G} / \mathrm{A}$ and $4895 \mathrm{~A} / \mathrm{G}-\mathrm{D}^{\prime}=$ 0.88 and $P<0.0001 ; 3813 \mathrm{~A} / \mathrm{G}$ and $4895 \mathrm{~A} / \mathrm{G}-$ $\mathrm{D}^{\prime}=0.76$ and $\left.P<0.0001\right)$. Due to this strong LD between polymorphisms, three frequent haplotypes accounted for $88 \%$ of the chromosomes investigated, $\mathrm{G}_{1359} \mathrm{~A}_{3813} \mathrm{~A}_{4895}$ (GAA), $\mathrm{G}_{1359} \mathrm{~A}_{3813} \mathrm{G}_{4895}$ (GAG) and $\mathrm{A}_{1359} \mathrm{~A}_{3813} \mathrm{~A}_{4895}$ (AAA), frequencies were 0.489, 0.182 and 0.212 , respectively. The other five haplotypes accounted together for less than $12 \%$ of the observed chromosomes. Because the haplotype derived from the three wild alleles corresponds to almost $50 \%$ of the haplotype frequencies, we tested the association assuming an additive effect of this haplotype GAA (absent, one copy or two copies) with BMI and WHR using a multiple linear regression analysis. An association 
Table 3

Multiple Linear Regression of BMI and WHR with CNR1 1359G/A genotypes (GG versus AG plus AA) and potential confounders

\begin{tabular}{lrcccccc}
\hline & \multicolumn{3}{c}{ BMI } & & \multicolumn{3}{c}{ WHR } \\
\cline { 2 - 5 } \cline { 6 - 8 } Variables & $\mathrm{B}$ & Std. Error & P-value & & $\mathrm{B}$ & Std. Error & P-value \\
\hline CNR1 1359A & 0.234 & 0.336 & 0.487 & & 0.003 & 0.005 & 0.519 \\
Age (years) & 0.021 & 0.012 & 0.092 & & 0.001 & 0.0001 & 0.0001 \\
Smoking & -0.405 & 0.347 & 0.243 & & 0.008 & 0.005 & 0.123 \\
Alcohol & -0.024 & 0.352 & 0.946 & & -0.011 & 0.005 & 0.029 \\
Physical inactivity & -0.186 & 0.344 & 0.589 & & 0.015 & 0.005 & 0.004 \\
Gender & -0.661 & 0.365 & 0.07 & & 0.065 & 0.005 & 0.0001 \\
HDL-Chol (mg/dL) & -0.055 & 0.015 & 0.0001 & & -0.0007 & 0.0001 & 0.002 \\
LDL-Chol (mg/dL) & 0.008 & 0.004 & 0.054 & & 0.00005 & 0.0001 & 0.415 \\
Triglycerides (mg/dL) & 0.011 & 0.002 & 0.0001 & & 0.0001 & 0.0001 & 0.0001 \\
Glycaemia (mg/dL) & 0.078 & 0.014 & 0.0001 & & 0.0007 & 0.0001 & 0.001 \\
\hline
\end{tabular}

Table 4

Multiple Linear Regression of BMI and WHR with CNR1 3813A/G genotypes (AA versus AG plus GG) and potential confounders

\begin{tabular}{lccccccc}
\hline & \multicolumn{3}{c}{ BMI } & & \multicolumn{3}{c}{ WHR } \\
\cline { 2 - 5 } \cline { 6 - 8 } Variables & $\mathrm{B}$ & Std. Error & P-value & & $\mathrm{B}$ & Std. Error & P-value \\
\hline CNR1 3813G & -0.08 & 0.409 & 0.837 & & 0.008 & 0.006 & 0.203 \\
Age (years) & 0.022 & 0.012 & 0.073 & & 0.001 & 0.0001 & 0.0001 \\
Smoke & -0.384 & 0.351 & 0.274 & & 0.008 & 0.005 & 0.112 \\
Alcohol & 0.035 & 0.358 & 0.923 & & -0.012 & 0.005 & 0.028 \\
Physical inactivity & -0.137 & 0.349 & 0.695 & & 0.014 & 0.005 & 0.005 \\
Gender & -0.523 & 0.37 & 0.158 & & 0.067 & 0.005 & 0.0001 \\
HDL-Chol (mg/dL) & -0.052 & 0.015 & 0.001 & & -0.0006 & 0.0001 & 0.004 \\
LDL-Chol (mg/dL) & 0.01 & 0.004 & 0.027 & & 0.00006 & 0.0001 & 0.376 \\
Triglycerides (mg/dL) & 0.012 & 0.002 & 0.0001 & & 0.0001 & 0.0001 & 0.0001 \\
Glycaemia (mg/dL) & 0.041 & 0.011 & 0.0001 & & 0.0004 & 0.0001 & 0.013 \\
\hline
\end{tabular}

with WHR was observed $(P=0.028)$ (Table 6$)$, although this $\mathrm{P}$-value is above the threshold of statistical significance after Bonferroni correction $(P=0.084)$. These results suggest that the presence of the block carrying the wild $4895 \mathrm{~A}$ allele was associated with a smaller WHR, as the association at the single SNP level pointed to a higher WHR for $4895 \mathrm{G}$ allele carriers. Therefore a contribution of a genetic variant at CNR1 gene in central obesity is suggested although it does not exclude the effect of other polymorphisms not investigated in the present study.

\section{Discussion}

We have genotyped three SNPs in the CNRI gene in a sample of individuals from Southern Brazil of European ancestry. Evidence of association of 4895A/G variant and WHR was detected which was consistent in single SNP and haplotype analyses. Although it is not expected for any of these three SNPs to be functional, it is possible that we have detected an association through linkage disequilibrium of nearby polymorphisms.
Obesity was measured using body mass index (BMI) and waist to hip ratio (WHR). The measurement of WHR was chosen instead of waist circumference (WC) because it has been suggested to be a superior predictor of cardiovascular disease associated with abdominal obesity, as long as it includes hip circumference, which is inversely associated to metabolic dysfunction, hypertension, and death [18].

Five previous publications $[1,12,22,23,28]$ have examined the possible association of CNR1 polymorphisms with obesity. The association between the 1359A allele with lower BMI found by Gazzerro et al. [12] has not been replicated in two other investigations from different populations [1,22]. Russo et al. [28] reported an association of the $3813 \mathrm{G}$ allele with several obesity related traits including waist circumference but not with the $4895 \mathrm{~A}>\mathrm{G}$ polymorphism. In the present study, we observed an association of the 4895 $A>G$ polymorphism with waist to hip ratio (WHR). Peeters et al. [23] recently reported an association of the CNR1 1359G/A variant with abdominal adiposity. In obese men, CNRI 1359A/A genotype was significantly associated with higher WHR and waist circumference. In the current study, we demonstrated that genetic vari- 
Table 5

Multiple Linear Regression of BMI and WHR with CNR1 4895A/G genotypes (AA versus AG plus GG) and potential confounders

\begin{tabular}{lccccccc}
\hline & \multicolumn{3}{c}{ BMI } & & \multicolumn{3}{c}{ WHR } \\
\cline { 2 - 5 } \cline { 6 - 8 } Variables & $\mathrm{B}$ & Std. Error & P-value & & $\mathrm{B}$ & Std. Error & P-value \\
\hline CNR1 4895G & 0.018 & 0.332 & 0.958 & & 0.012 & 0.005 & 0.014 \\
Age (years) & 0.024 & 0.012 & 0.052 & & 0.001 & 0.0001 & 0.0001 \\
Smoke & -0.367 & 0.349 & 0.294 & & 0.009 & 0.005 & 0.076 \\
Alcohol & 0.07 & 0.355 & 0.844 & & -0.012 & 0.005 & 0.022 \\
Physical inactivity & -0.119 & 0.346 & 0.731 & & 0.015 & 0.005 & 0.003 \\
Gender & -0.579 & 0.368 & 0.116 & & 0.067 & 0.005 & 0.0001 \\
HDL-Chol (mg/dL) & -0.049 & 0.015 & 0.001 & & -0.0006 & 0.0001 & 0.007 \\
LDL-Chol (mg/dL) & 0.009 & 0.004 & 0.043 & & 0.00006 & 0.0001 & 0.331 \\
Triglycerides (mg/dL) & 0.012 & 0.002 & 0.0001 & & 0.0001 & 0.0001 & 0.0001 \\
Glycaemia (mg/dL) & 0.04 & 0.011 & 0.0001 & & 0.0004 & 0.0001 & 0.015 \\
\hline
\end{tabular}

Table 6

Multiple Linear Regression of BMI and WHR with GAA haplotype (additive effect) and potential confounders

\begin{tabular}{lcccccl}
\hline & \multicolumn{3}{c}{ BMI } & & \multicolumn{3}{c}{ WHR } \\
Variables & B & Std. Error & P-value & B & Std. Error & P-value \\
\hline Haplotype GAA & 0.021 & 0.234 & 0.929 & -0.008 & 0.003 & 0.028 \\
Age (years) & 0.023 & 0.012 & 0.061 & 0.001 & 0.0001 & 0.0001 \\
Smoke & -0.39 & 0.349 & 0.265 & 0.009 & 0.005 & 0.081 \\
Alcohol & 0.042 & 0.355 & 0.905 & -0.012 & 0.005 & 0.025 \\
Physical inactivity & -0.132 & 0.346 & 0.703 & 0.015 & 0.005 & 0.003 \\
Gender & -0.549 & 0.367 & 0.135 & 0.067 & 0.005 & 0.0001 \\
HDL-Chol (mg/dL) & -0.048 & 0.015 & 0.001 & -0.0006 & 0.0001 & 0.007 \\
LDL-Chol (mg/dL) & 0.009 & 0.004 & 0.037 & 0.00005 & 0.0001 & 0.375 \\
Triglycerides (mg/dL) & 0.012 & 0.002 & 0.0001 & 0.0002 & 0.0001 & 0.0001 \\
Glycaemia (mg/dL) & 0.04 & 0.011 & 0.0001 & 0.0004 & 0.0001 & 0.016 \\
\hline
\end{tabular}

ation at $C N R 1$ gene might play a role in abdominal obesity. Although we did not find an association with this polymorphism, these data reinforce the relevant effect of the CNRI gene in abdominal fat accumulation and distribution. These inconsistencies among studies could be explained by different genetic backgrounds or environmental factors, as for other gene variants, the impact of environmental factors such as diet, exercise, and climatic temperatures may obscure the expression of detectable and consistent phenotypes across human populations. Nevertheless these results taken together suggest a role for these CNR1 polymorphisms on appetite control, although caution is needed in reporting which polymorphism might be involved.

A recent investigation showed that CNR1 mRNA expression was negatively correlated with visceral fat mass. They also identified endocannabinoid plasma concentrations, in addition to body fat mass, as significant predictors of $\mathrm{CB} 1$ receptor gene expression. Once CB1 gene expression in visceral and subcutaneous adipose tissues were closely correlated, it suggest that CB1 gene expression in subcutaneous adipose tissue may be an acceptable surrogate for CB1 gene expression in visceral adipose tissue [4]. Although it is more like- ly to expect that genetic variation contributes to decrease rather than increase the receptor activity, leading to underweight and anorexia instead of overweight and obesity, this finding suggests that the association of the $4895 \mathrm{G}$ allele with WHR observed in the present investigation could be due to a higher expression of the CNRl gene. Meanwhile, no functional studies were carried out to test if this gene is differentially expressed according to $4895 \mathrm{~A} / \mathrm{G}$ or other gene variants. Because many of the regulatory regions of the gene are largely unknown, and the inconsistencies of which polymorphism is associated with obesity related traits, it is likely that the functional polymorphisms have yet to be identified.

The present study has some limitations. When studying polygenic traits, it is important to keep in mind that, generally, each gene contributes with a small to moderate percentage of the trait variance, which implies that the same disorder in different groups may be caused by different combinations of polygenes [5]. This fact could explain the small effect of the CNRI 4895 polymorphism in the regression model, in spite of the statistical significance. Although these polymorphisms may be considered representative for variations 
at this locus [11,33], the observed associations could be spurious (type I error) due to multiple statistical comparisons. We performed the Bonferroni procedure for multiple testing corrections. However, when the probability of the type I error (false positive) decreases, the probability of the type II error (false negative) increases. The appropriate application of multiple testing corrections is not always clear [24] and therefore the two P-values (before and after corrections) are shown. Indeed, independent replication of significant associations in different populations is an important aspect of a credible genetic association result.

In summary, the results presented here showed evidence for the association of $C N R I$ gene variation with central obesity phenotype. As only few recent studies showed association of the CNR1 polymorphisms and obesity-related traits, in the current study we preferred to consider our findings as exploratory. Despite of our results being consistent with the hypothesis that the CNRl gene is a genetic contributor to abdominal obesity, replications in other populations are obviously warranted.

\section{Acknowledgments}

The authors thank the financial support provided by Conselho Nacional de Desenvolvimento Científico e Tecnológico (CNPq, Brazil), Programa de Apoio de Núcleos de Excelência (PRONEX, Brazil), Institutos do Milênio (CNPq, Brazil), and Fundação de Amparo a Pesquisa do Rio Grande do Sul (FAPERGS). We are also grateful to Fabiana M Andrade, Marilu Fiegenbaum, Silvana de Almeida and Marcel Arsand for help in sample collection, and to Deise Friedrich for technical assistance.

\section{References}

[1] J. Aberle, I. Fedderwitz, N. Klages, E. George and F.U. Beil, Genetic variation in two proteins of the endocannabinoid system and their influence on body mass index and metabolism under low fat diet, Hormone and metabolic research 39 (2007), 395-397.

[2] K.G.M.M. Alberti and P.Z. Zimmet, Definition, diagnosis and classification of diabetes mellitus and its complications. Part 1: diagnosis and classification of diabetes mellitus. Provisional report of a WHO consultation, Diabetic medicine: a journal of the British Diabetic Association 15 (1998), 539-553.

[3] M. Bensaid, M. Gary-Bobo, A. Esclangon, J.P. Maffrand, G. Le Fur, F. Oury-Donat and P. Soubrié, The cannabinoid CB1 receptor antagonist SR141716 increases Acrp30 mRNA expression in adipose tissue of obese fa/fa rats and in cultured adipocyte cells, Molecular pharmacology 63 (2003), 908-914.
[4] M. Blüher, S. Engeli, N. Kloting, J. Berndt, M. Fasshauer, S. Bátkai, P. Pacher, M.R. Schön, J. Jordan and M. Stumvoll, Dysregulation of the peripheral and adipose tissue endocannabinoid system in human abdominal obesity, Diabetes $\mathbf{5 5}$ (2006), 3053-3060.

[5] D.E. Comings, Why different rules are required for polygenic inheritance: lessons from studies of the DRD2 gene, Alcohol 16 (1998), 61-70.

[6] D. Cota, G. Marsicano, M. Tschöp, Y. Grübler, C. Flachskamm, M. Schubert, D. Auer, A. Yassouridis, C. ThöneReineke, S. Ortmann, F. Tomassoni, C. Cervino, E. Nisoli, A.C. Linthorst, R. Pasquali, B. Lutz, G.K. Stalla and U. Pagotto, The endogenous cannabinoid system affects energy balance via central orexigenic drive and peripheral lipogenesis, The Journal of clinical investigation 112 (2003), 423-431.

[7] V. Di Marzo, M. Bifulco and L. De Petrocellis, The endocannabinoid system and its therapeutic exploitation, Nature reviews. Drug discovery 3 (2004), 771-784.

[8] V. Di Marzo, S.K. Goparaju, L. Wang, J. Liu, S. Bátkai, Z. Járai, F. Fezza, G.I. Miura, R.D. Palmiter, T. Sugiura and G. Kunos, Leptin-regulated endocannabinoids are involved in maintaining food intake, Nature 410 (2001), 822-825.

[9] E. Fride, Y. Ginzburg, A. Breuer, T. Bisognot, V. Di Marzo and R. Mechoulam, Critical role of the endogenous cannabinoid system in mouse pup suckling and growth, European journal of pharmacology 419 (2001), 207-214.

[10] W.T. Friedewald, R.I. Levy and D.S. Fredrickson, Estimation of the concentration of low-density lipoprotein cholesterol in plasma, without use of the preparative ultracentrifuge, Clinical chemistry 18 (1972), 499-502.

[11] D. Gadzicki, K. Müller-Vahl and M. Stuhrmann, A frequent polymorphism in the coding exon of the human cannabinoid receptor (CNR1) gene, Molecular and cellular probes $\mathbf{1 3}$ (1999), 321-323.

[12] P. Gazzerro, M.G. Caruso, M. Notarnicola, G. Misciagna, V. Guerra, C. Laezza and M. Bifulco, Association between cannabinoid type-1 receptor polymorphism and body mass index in a southern Italian population, International journal of obesity (2005) 12 (2007), 908-912.

[13] M.R. Hoehe, L. Caenazzo, M.M. Martinez, W.T. Hsieh, W.S. Modi, E.S. Gershon and T.I. Bonner, Genetic and physical mapping of the human cannabinoid receptor gene to chromosome 6q14-q15, The New biologist 3 (1991), 880-885.

[14] T.L Horvath, Endocannabinoids and the regulation of body fat: the smoking is clearing. The Journal of clinical investigation 112 (2003), 323-326.

[15] A.C. Howlett, The cannabinoid receptors. Prostaglandins \& other lipid mediator 68-69 (2002), 619-631.

[16] A.C. Howlett, M. Glass, M. Dragunow and R.L. Faull, Cannabinoid receptors in the human brain: a detailed anatomical and quantitative autoradiographic study in the fetal, neonatal and adult human brain, Neuroscience 77 (1997), 299-318.

[17] N. Jamshidi and D.A. Taylor, Anandamide administration into the ventromedial hypothalamus stimulates appetite in rats, British journal of pharmacology 134 (2001), 1151-1154.

[18] L. de Koning, A.T. Merchant, J. Pogue and S.S. Anand, Waist circumference and waist-to-hip ratio as predictors of cardiovascular events: meta-regression analysis of prospective studies, European heart journal 28 (2007), 850-851.

[19] D.K. Lahiri and J.I. Nurnberger, Rapid non-enzymatic method for the preparation of HMW DNA from blood for RFLP studies, Nucleic acids research 19 (1991), 5444. 
[20] J.C. Long, R.C. Williams and M. Urbanek, An E-M algorithm and testing strategy for multiple-locus haplotypes, American journal of human genetics 56 (1995), 799-810.

[21] P. Monteleone, I. Matias, V. Martiadis, L. De Petrocellis, M. Maj and V. Di Marzo, Blood levels of the endocannabinoid anandamide are increased in anorexia nervosa and in bingeeating disorder, but not in bulimia nervosa, Neuropsychopharmacology 30 (2005), 1216-1221.

[22] T.D. Müller, K. Reichwald, A.K. Wermter, G. Brönner, T.T. Nguyen, S. Friedel, K. Koberwitz, S. Engeli, P. Lichtner, T. Meitinger, H. Schäfer, J. Hebebrand and A. Hinney, No evidence for an involvement of variants in the cannabinoid receptor gene (CNR1) in obesity in German children and adolescents, Molecular genetics and metabolism 90 (2007), 429434.

[23] A. Peeters, S. Beckers, I. Mertens, W. Van Hul and L. Van Gaal, The G1422A variant of the cannabinoid receptor gene (CNR1) is associated with abdominal adiposity in obese men, Endocrine 31 (2007), 138-141.

[24] T.V. Perneger, What's wrong with Bonferroni adjustments, BMJ 316 (1998), 1236-1238.

[25] R.G. Pertwee, Cannabinoids and the gastrointestinal tract. Gut 48 (2001), 859-867.

[26] D. Piomelli, The molecular logic of endocannabinoid signaling, Nature reviews. Neuroscience 4 (2003), 873-884.

[27] M. Rinaldi-Carmona, F. Barth, M. Héaulme, D. Shire, B. Calandra, C. Congy, S. Martinez, J. Maruani, G. Néliat, D.
Caput, P. Ferrara, P. Soubrié, J.C. Brelière and G. Le Fur, SR141716A, a potent and selective antagonist of the brain cannabinoid receptor, FEBS letters 350 (1994), 240-244.

[28] P. Russo, P. Strazzullo, F.P. Cappuccio, D.A. Tregouet, F. Lauria, M. Loguercio, G. Barba, M. Versiero and A. Siani, Genetic variations at the endocannabinoid type 1 receptor gene (CNR1) are associated with obesity phenotypes in men, The Journal of clinical endocrinology and metabolism 92 (2007), 2382-2386.

[29] F.M. Salzano and M.C. Bortolini, The evolution and genetics of Latin American populations, Cambridge University Press, Cambridge, 2002.

[30] W.C. Willett, Anthropometric measures and body composition, Oxford University Press, New York, 1998.

[31] World Health Organization, Physical status: the use and interpretation of anthropometry, World Health Organization, Geneva, 1995.

[32] World Health Organization, Obesity: preventing and managing the global epidemic. Report of a WHO consultation on obesity, Geneva, 3-5 June 1997, World Health Organization, Geneva, 1998.

[33] P.W. Zhang, H. Ishiguro, T. Ohtsuki, J. Hess, F. Carillo, D. Walther, E.S. Onaivi, T. Arinami and G.R. Uhl, Human cannabinoid receptor 1: 5' exons, candidate regulatory regions, polymorphisms, haplotypes and association with polysubstance abuse, Molecular psychiatry 9 (2004), 916-931. 


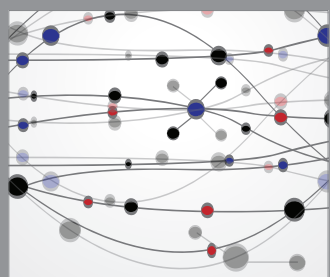

The Scientific World Journal
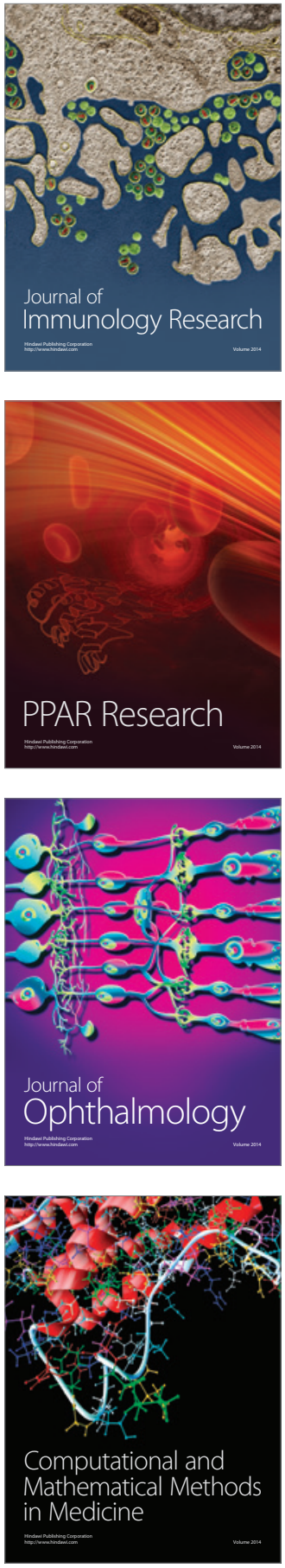

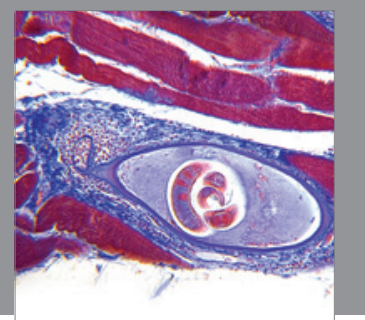

Gastroenterology

Research and Practice
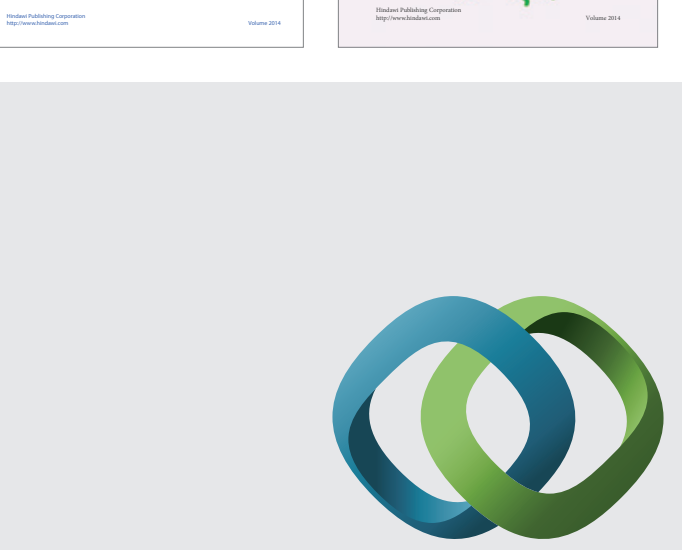

\section{Hindawi}

Submit your manuscripts at

http://www.hindawi.com
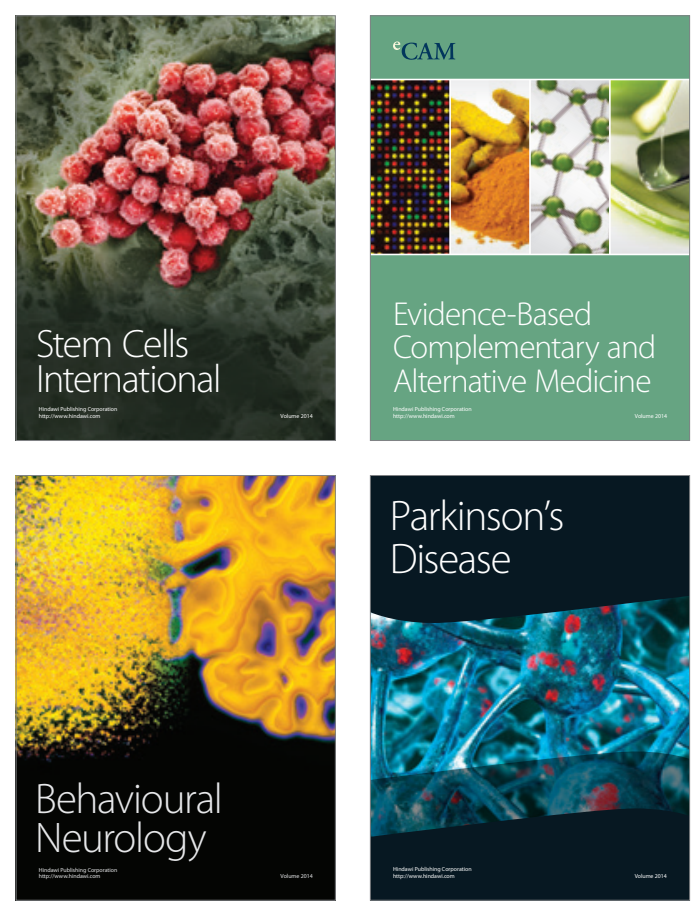

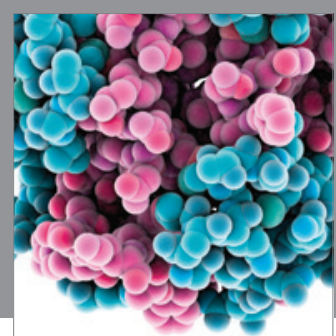

Journal of
Diabetes Research

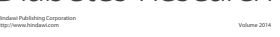

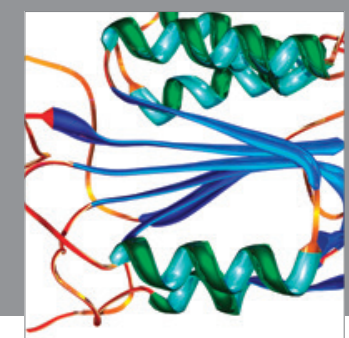

Disease Markers
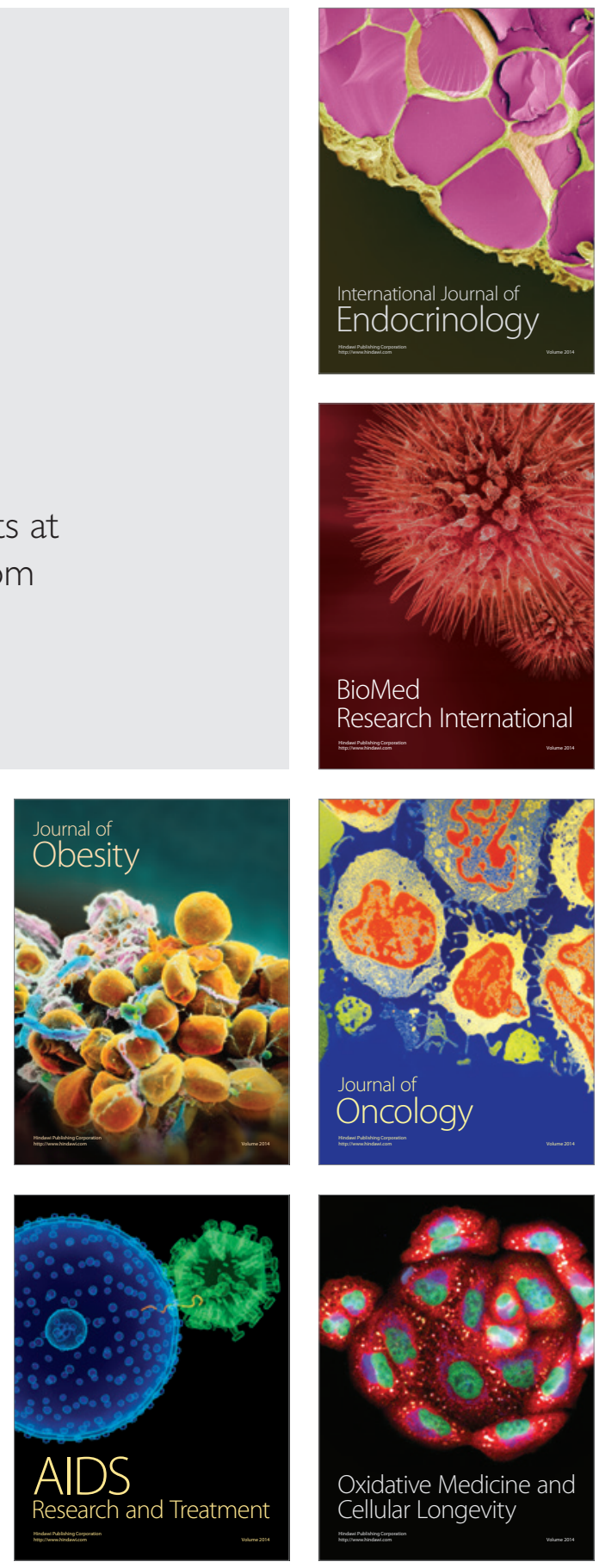